九州大学学術情報リポジトリ

Kyushu University Institutional Repository

Redescriptions of the Hawaiian Spiders of Tetragnatha Described by Simon (Araneae, Tetragnathidae)

Okuma, Chiyoko

Entomological Laboratory, Faculty of Agriculture, Kyushu University

https://doi.org/10.5109/23919

出版情報: 九州大学大学院農学研究院紀要. 33 (1/2), pp.77-86, 1988-10. Kyushu University バージョン：

権利関係 : 


\title{
Redescriptions of the Hawaiian Spiders of Tetragnatha Described by Simon (Araneae, Tetragnathidae)*
}

\author{
Chiyoko Okuma \\ Entomological Laboratory, Faculty of Agriculture, \\ Kyushu University, Fukuoka 812, Japan. \\ (Received June 17, 1988)
}

\begin{abstract}
Seven species of the Hawaiian spiders of Tetragnatha Latreille described by Simon in 1900, i. e., cuneiventris, huwaiensis, kauaiensis, netrix, perkinsi, restricta and unicifera are redescribed and illustrated based on the type specimens which are preserved in the Museum National d'Histoire Naturelle, Paris.
\end{abstract}

Simon (1900) recorded 9 species of Tetragnatha from the Hawaiian Islands, viz., 8 new species and one named species, T.mandibulata Walckenaer. This paper presents the redescriptions of the types of 7 Hawaiian Tetragnathu described by Simon, based on the materilas preserved in the Museum National d'Histoire Naturelle, Paris. Tetragnathu sobrina Simon was not included in this paper because the type is not found in the Muséum.

So far as I know, T. mandibulata is a cosmopolitan species while the 8 species described by Simon are endemic to the Hawaiian Islands.

I am grateful to Dr. Michel Hubert and Dr. J. Heurtault of the Museum National D'Histoire Neturell, Paris for lending me the types of Simon's species. I am also grateful to Prof. Y. Hirashima of Kyushu University for his kind guidance and careful reading of the manuscript of this paper.

Tetragnatha cuneiventris Simon, 1900 (Fig. 1)

Tetragnatha cuneiventris Simon, 1900, Fauna Hawaiiensis, 2(5) : 475.

Male. Anterior row of eyes occupying full width of head, posterior row of eyes about as wide as anterior one ; viewed from above, anterior row somewhat strongly recurved, posterior row moderately recurved, so that lateral eyes slightly closer than median eyes ; central ocular quadrangle with posterior ocular width slightly larger than anterior ocular width. Basal segment of chelicerae about 0.8 times as long as carapace ; (a) bifurcated at tip, (Gu) present, (sl) slightly directed backward at tip, (T) somewhat large, (rsu) 5 in number, (AXl) present, (G1) and (L2) somewhat strong, (L3) situated in fang furrow ; fang unarmed. Femur of first leg probably with 9 spines (actually broken) ; spines not so long. Tibia of palpus slightly longer than patella as shown in Fig. 1, F ; tip of conductor a large recurved hook. Abdomen lost.

Color: Chelicerae, carapace and legs pale reddish brown.

* Contribution from the Entomological Laboratory, Faculty of Agriculture, Kyushu University, Fukuoka (Ser. 3, No. 276). 


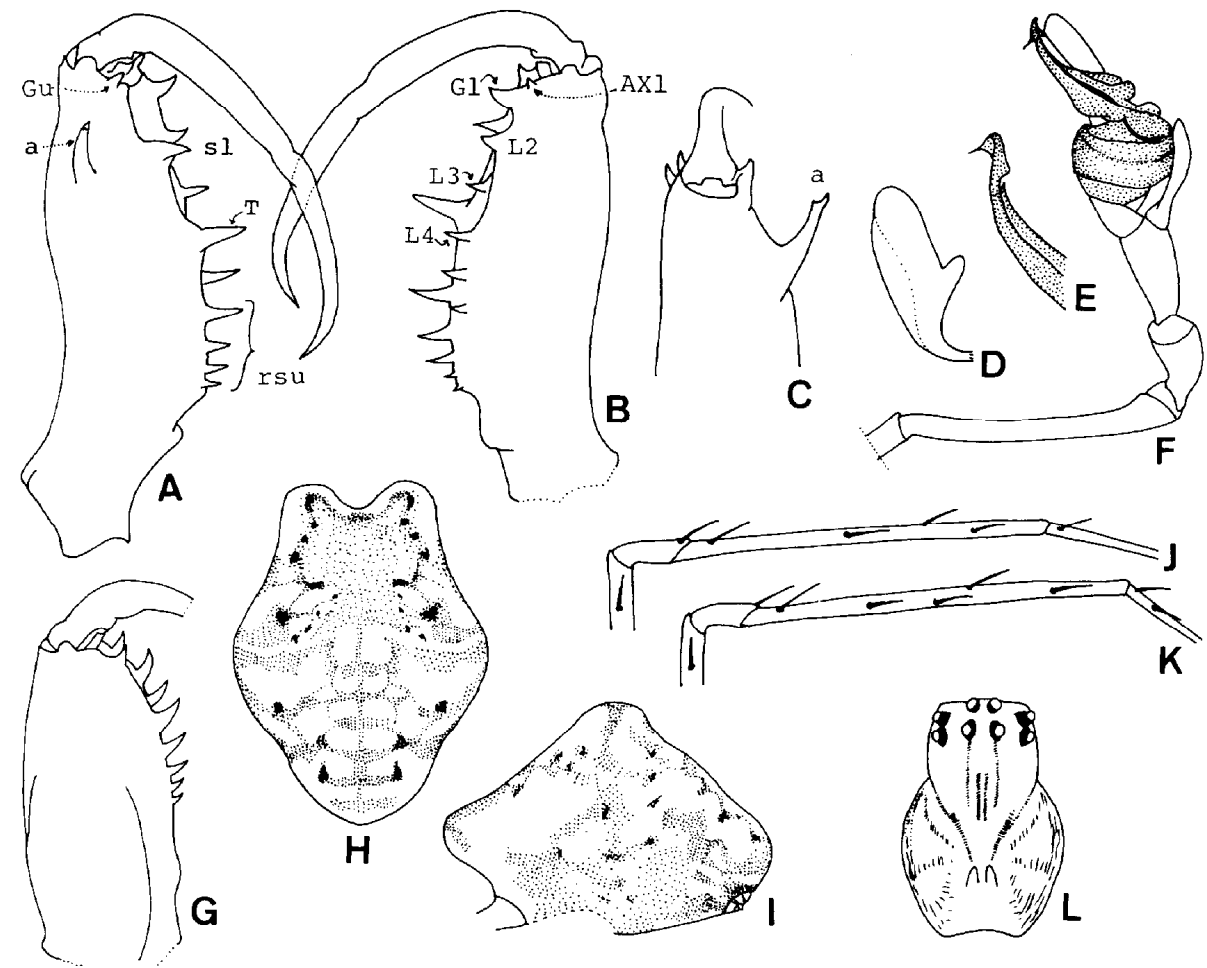

Fig. 1. Tetragnatha cuneiventris Simon. A : Left chelicera of male, upper view. B : Ditto, lower view. C : Ditto, lateral view. D : Paracymbium of male. E : Distal portion of conductor of male. F : Left palpus of male, outer lateral view. G : Left chelicera of female, upper view. $\mathrm{H}$ : Abdomen of female, upper view. I : Ditto, lateral view (genital fold broken). J : Tibia of first leg of male, inner lateral view. K : Ditto, outer lateral view. L: Carapace of male, upper view.

Carapacial length $2.2 \mathrm{~mm}$, width $1.5 \mathrm{~mm}$; abdomen lost; cheliceral length $1.8 \mathrm{~mm}$. Female. One teneral specimen ; generally weak, particularly carapace and legs. Abdomen short, gibbous dorsally as shown in Fig. 1, I ; genital fold broken.

Color : Chelicerae, carapace and legs similar to male, abdomen generally pale whitish brown, with dasky markings and covered with whitich spangles.

Body lengh, exclusive of chelicera, $5.0 \mathrm{~mm}$; carapacial length $1.5 \mathrm{~mm}$, width 1.0 $\mathrm{mm}$; abdominal length $3.7 \mathrm{~mm}$, width $2.5 \mathrm{~mm}$, height $2.4 \mathrm{~mm}$; cheliceral length 1.05 $\mathrm{mm}$.

Tetragnatha hawaiensis Simon, 1900 (Fig. 2)

Tetragnatha hawaiensis Simon, 1900, Fauna Hawaiiensis, 2(5): 470.

Female. Anterior row of eyes occupying full width of head, posterior row of eyes slightly wider than anterior one ; viewed from above, anterior row somewhat strongly 


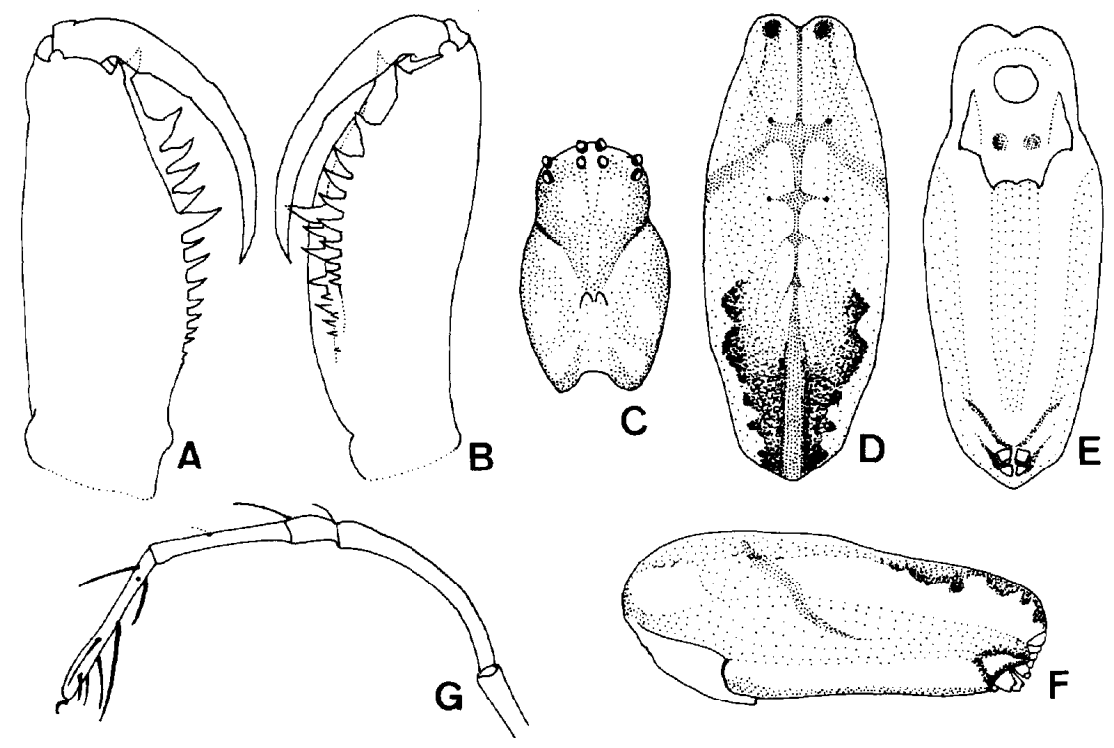

Fig. 2. Tetragnatha huwaiensis Simon, (Female). A: Left chelicera, upper view. B: Ditto, lower view. C : Carapace, upper view. D : Abdomen, upper view. E : Ditto, lower view. F : Ditto, lateral view. G : Left palpus, outer lateral view.

recurved, posterior row slightly recurved, so that lateral eyes slightly closer than median eyes ; central ocular quadrange, with posterior ocular width slightly larger than anterior ocular width. Basal segment of chelicera about 0.7 times as iong as carapace, without particular features. Legs damaged ; but femur of 1st legs probably provided with 3-4 spines. Tarsus of palpus with many long spines as shown in Fig. 2, G. Abdomen about 2.4 times as long as broad ; distal end of abdomen somewhat overhanging spinnerets ; genital fold as shown in Fig. 2, E.

Color : Chelicera, carapace and legs pale reddish brown ; abdomen generally pale yellowish brown with dusky markings as shown in Fig. 2, D, E and F.

Body length exclusive of chelicera, $10.8 \mathrm{~mm}$; carapacial length $3.8 \mathrm{~mm}$, width 2.5 $\mathrm{mm}$; abdominal length $7.1 \mathrm{~mm}$, width $3.1 \mathrm{~mm}$; cheliceral length $2.7 \mathrm{~mm}$.

Male unknown.

\section{Tetragnatha kauaiensis Simon, 1900 (Fig. 3)}

Tetragnathu kauaiensis Simon, 1900, Fauna Hawaiiensis, 2(5) : 472.

Male. Anterior row of eyes occupying full width of head, posterior row of eyes evidently narrower than anterior one; viewed from above, anterior row somewhat strongly recurved, posterior row slightly recurved, so that lateral eyes slightly closer than median eyes ; central ocular quadrangle, with posterior ocular width slightly larger than anterior ocular width. Basal segment of chelicera about 0.7 times as long as carapace ; (a) meanly bifurcated at tip, $(\mathrm{Gu})$ spatulate, (sl) small, ( $\mathrm{AXl}$ ) present, (Gl) somewhat large, (rsl) 8 in number ; fang unarmed. Femur of first leg probably with 12 


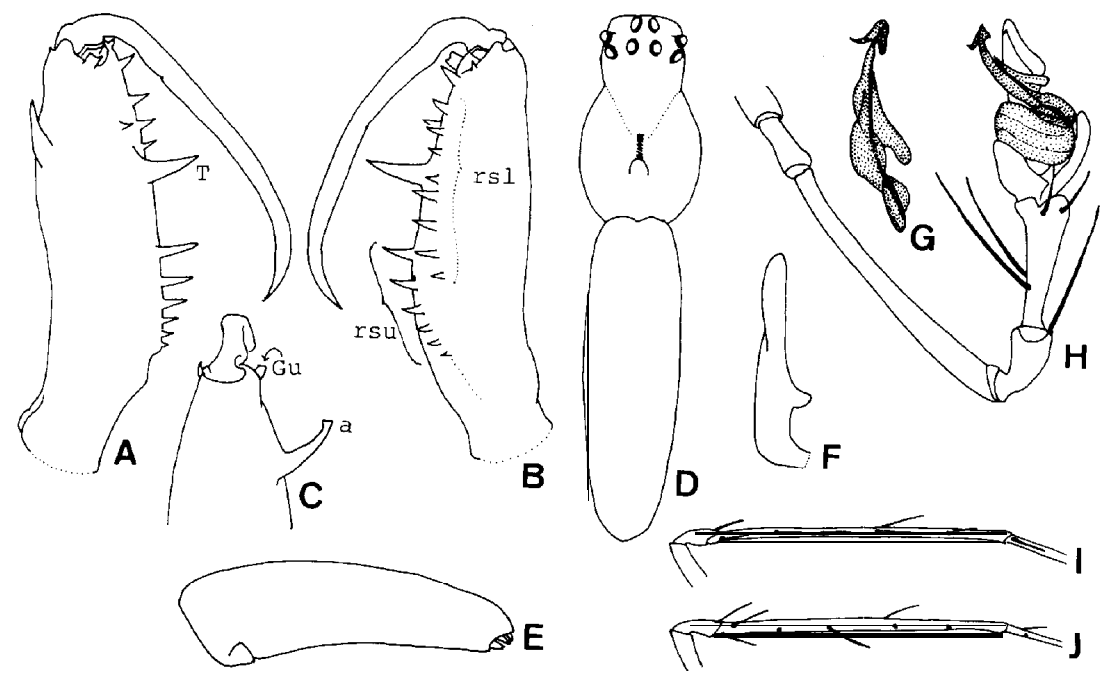

Fig. 3. Tetragnathakauaiensis Simon, (Male). A: Left chelicera, upper view. B: Ditto, lower view. C : Ditto, lateral view. D : Body, upper view. E : Abdomen, lateral view. F: Paracymbium. G : Conductor and embolus. H : Left palpus, outer lateral view. I : Tibia of first leg, inner lateral view. J : Ditto, outer lateral view.

spines (actually broken) ; first tibia with long spines as shown in Fig. 3, I and J. Patella and tibia of palpus with long spines; tip of conductor a large recurved hook. Abdomen about 3.5 times as long as broad; without particular features.

Color : Generally pale whitish yellowish brown ; abdomen without any markings, covered with few small spangles.

Body length, exclusive of chelicera $5.8 \mathrm{~mm}$; carapacial length $2.3 \mathrm{~mm}$, width 1.5 $\mathrm{mm}$; abdominal length $3.5 \mathrm{~mm}$, width $1.0 \mathrm{~mm}$; cheliceral length $1.6 \mathrm{~mm}$.

Female. lost.

Tetragnatha netrix Simon, 1900 (Fig. 4)

Tetragnathanetrix Simon, 1900, Fauna Hawaiiensis, 2(5): 468.

Male. Anterior row of eyes occupying full width of head, posterior row of eyes evidently narrower than anterior one; viewed from above, two rows nearly parallel and recurved. Basal segment of chlicera about 0.7 times as long as carapace ; (a) bifurcated at tip, $(\mathrm{Gu})$ present, (sl) directed forward, (T) strikingly large and thick, (rsu) 6 in number, $(\mathrm{AXl})$ present, $(\mathrm{Gl})$ long and large, (rsl) 6 in number ; fang unarmed. Legs damaged ; but femur of 1st legs probably provided with 3-4 spines. Tibia of palpus about 2 times longer than patella as shown in Fig. 4, M ; tip of conductor narrow and recurved. Abdomen about 4.5 times as long as broad, with a small tail overhanging spinnerets.

Color: Chelicera, carapace and legs pale reddish brown; head slightly dark ; abdomen generally whitish pale brown, with several pairs of brown dots dorsally as 


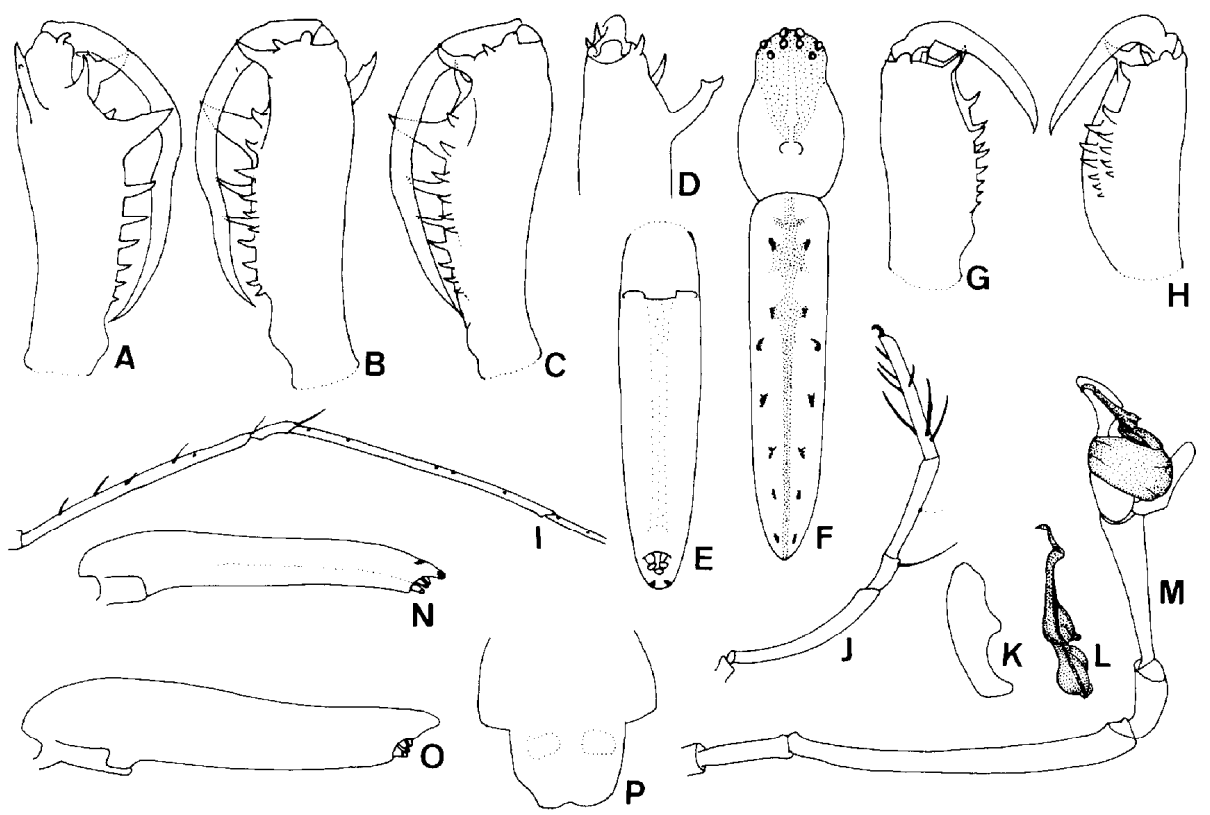

Fig. 4. Tetragnatha netrix Simon. A : Left chelicera of male, upper view. B and C : Ditto, lower view. D : Ditto, lateral view. E : Abdomen of male, lower view. F : Male. G : Left chelicera of female, upper view. H : Ditto, lower view. I : Right first leg of female, outer lateral view. J : Left palpus of female, outer lateral view. K :Paracymbium of male. L: Conductor and embolus of male. M : Left palpus of male, outer lateral view. $\mathrm{N}$ : Lateral view of abdomen, male. 0 : Ditto, female. P : Genital fold of female.

shown in Fig. 4, F.

Female. Arrangement of eyes nearly as in male. Basal segment of chelicera slightly longer than one-half of carapace, without particular features. Femur of first leg probably with $8-9$ spines (actually broken) ; spines not so long as shown in Fig. 4, I. Tarsus of palpus with many long spines. Abdomen nearly as in male ; genital fold as shown in Fig. 4, p.

Color : Similar to male.

Body length, exclusive of chelicerae, $10.0 \mathrm{~mm}$; carapacial length $2.8 \mathrm{~mm}$, width $1.7 \mathrm{~mm}$; abdominal length $7.3 \mathrm{~mm}$, width $1.6 \mathrm{~mm}$; cheliceral length $1.5 \mathrm{~mm}$.

Tetragnatha perkinsi Simon, 1900 (Figs. 5 and 6)

Tetragnatha perkinsi Simon, 1900, Fauna Hawaiiensis, Z(5) : 470.

Male. Anterior row of eyes occupying full width of head, posterior row of eyes slightly narrower than anterior one; viewed from above, anterior row somewhat strongly recurved, posterior row slightly recurved, so that lateral eyes slightly closer than median eyes ; central ocular quadrangle, with posterior ocular width slightly 

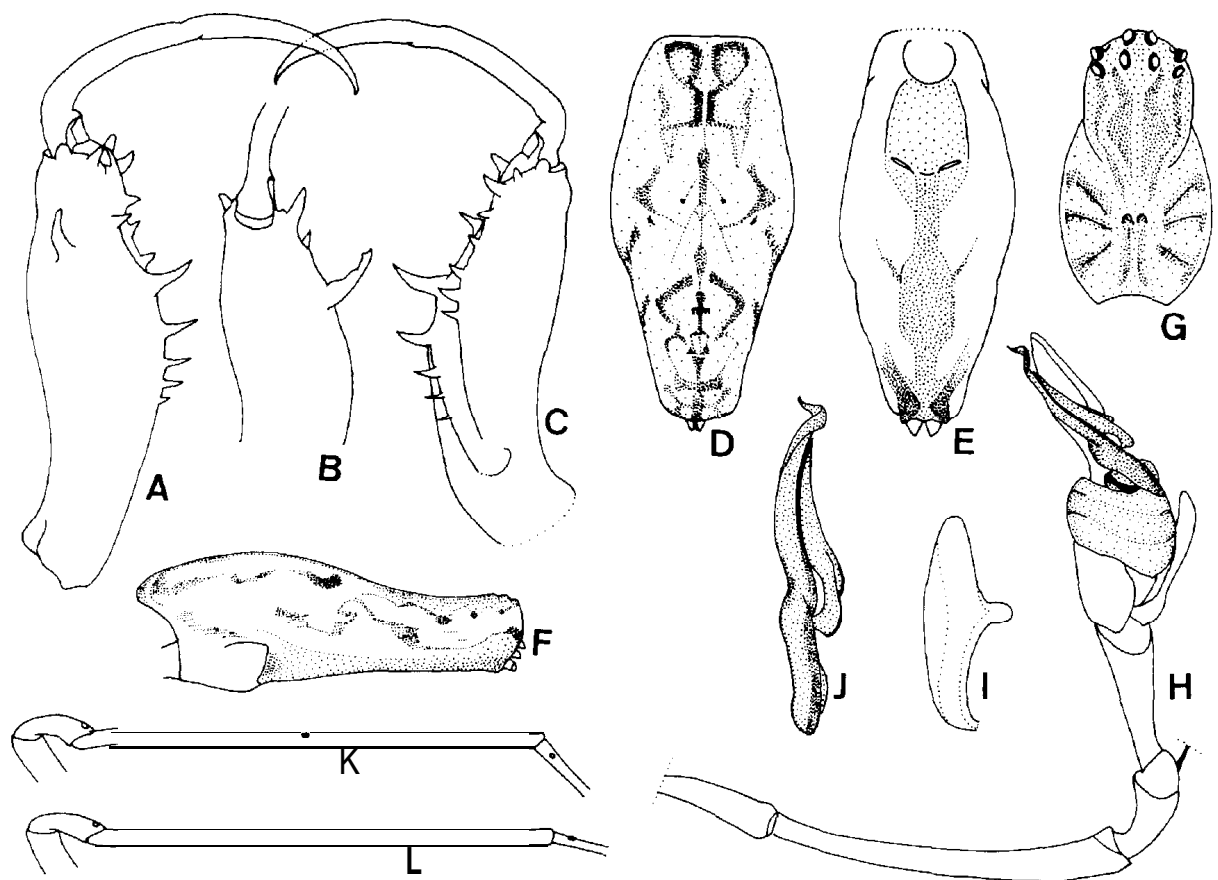

Fig. 5. Tetragnatha perkinsi Simon, (Male). A : Left chelicera, upper view. B : Ditto, lateral view. C : Ditto, lower view. D : Abdomen, upper view. E : Ditto, lower view. F : Ditto, lateral view. G : Carapace, upper view. H : Left palpus, outer lateral view. I : Paracymbium. J : Conductor and embolus. K : Tibia of first leg, inner lateral view. L : Ditto, outer lateral view.

larger than anterior ocular width. Basal segment of chelicera about 0.8 times as long as carapace ; (a) meanly bifurcated at tip, $(\mathrm{Gu})$ present, (sl) directed sideward at tip, (T) moderately large, (rsu) 4 in number, (AXl) present, (Gl) somewhat large; (rsl) 5 in number ; fang unarmed. Femur of first leg probably with 13-14 spines (actually broken). Tibia of palpus about 1.5 times longer than patella; without spines ; tip of conductor narrow and recurved. Abdomen about 2 times as long as broad; distal end of abdomen slightly over hanging spinnerets.

Color : Chelicera, carapace and legs pale reddish brown ; carapace with somewhat dusky markings as shown in Fig. 5, G ; abdomen generally whitish pale brown with dusky markings dorsally, with a central dusky stripe ventrally.

Body length exclusive of chelicera $7.7 \mathrm{~mm}$; carapacial length $3.1 \mathrm{~mm}$, width 2.1 $\mathrm{mm}$; abdominal length $4.6 \mathrm{~mm}$, width $2.1 \mathrm{~mm}$; cheliceral length $2.4 \mathrm{~mm}$.

Female. Arrangement of eyes nearly as in male. Basal segment of chelicera slightly longer than one-half of carapace, without particular features. Femur of first leg probably with 10 spines (actually broken). Tarsus of palpus with many long spines. Abdomen slightly shorter than 2 times as long as broad; distal end of abdomen slightly overhanging spinnerets. 


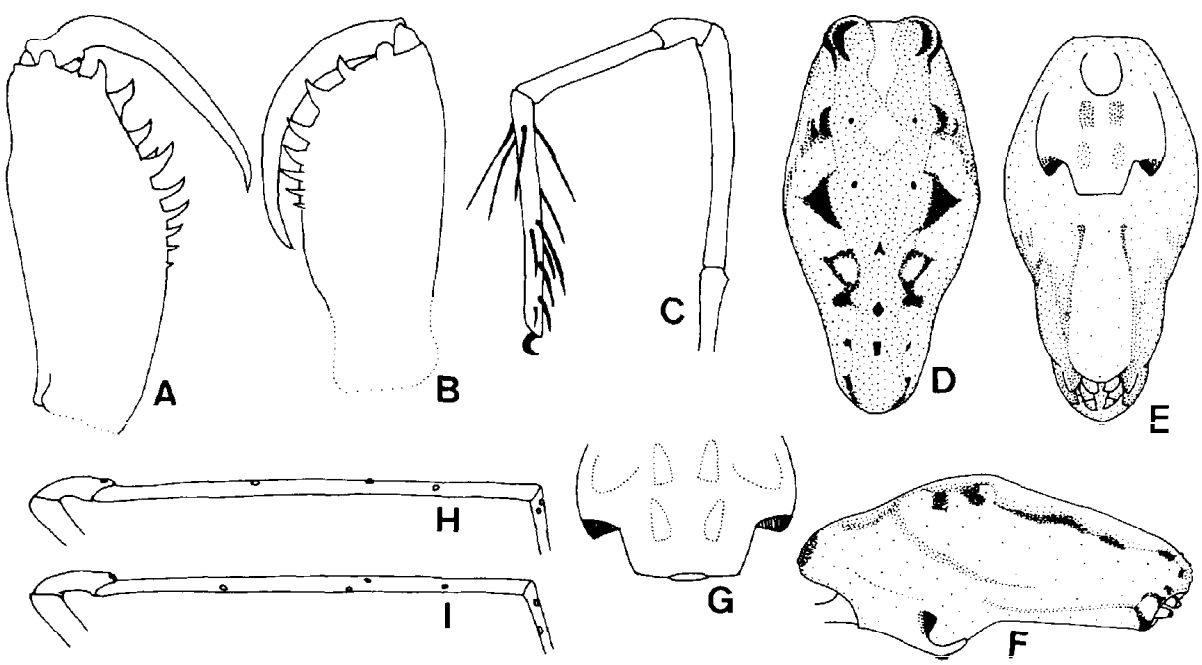

Fig. 6. Tetragnatha perkinsi Simon, (Female). A: Left chelicera, upper view. B : Ditto, lower view. C: Left palpus, outer lateral view. D: Abdomen, upper view. E: Ditto, lower view. F: Ditto, lateral view. G : Genital fold. H : Tibia of first leg, inner lateral view. I : Ditto, outer lateral view.

Color : Chelicera, carapace and legs pale yellowish brown; legs with many small dusky spots ; abdomen generally pale brown with dusky markings as shown in Fig. 6, $\mathrm{D}, \mathrm{E}$ and $\mathrm{F}$.

Body length exclusive of chelicera $9.9 \mathrm{~mm}$; carapacial legth $3.5 \mathrm{~mm}$, width 2.2 $\mathrm{mm}$; abdominal length $6.4 \mathrm{~mm}$, width $3.4 \mathrm{~mm}$; cheliceral length $2.2 \mathrm{~mm}$.

\section{Tetragnatha restricta Simon, 1900 (Fig. 7)}

Tetragnatha restricta Simon, 1900, Fauna Hawaiiensis, 2(5): 473.

Male. Anterior row of eyes occupying full width of head, posterior row of eyes slightly narrower than anterior one ; viewed from above, two rows nearly parallel and recurved. Basal segment of chelicera about 0.7 times as long as carapace ; (a) slightly bifurcated at tip, $(\mathrm{Gu})$ absent, (sl) small, directed forward, (T) moderately large, (rsu) 5 in number, (AXl) absent, (Gl) somewhat long, (rsl) 5 in number ; fang unarmed. Lags damaged. Tibia of palpus without spines, slightly longer than patella as shown in Fig. 7, D. Tip of conductor largely recurved. Abdomen lost.

Color : Carapace although it almost faded, with a pattern of pale yellowish brown and pale reddish brown as shown in Fig. 7, Q.

Carapacial length $1.7 \mathrm{~mm}$, width $1.3 \mathrm{~mm}$ : cheliceral length $1.25 \mathrm{~mm}$.

Female. Arrangement of eyes nearly as in male. Basal segment of chelicera slightly longer than one-half of carapace, without particular features. Femur of first leg probably with 11-12 spines (actually broken) ; tibia of first leg with long spines as shown in Fig. 7, $\mathrm{J}$ and $\mathrm{K}$. Palpus with long spines as shown in Fig. 7, $\mathrm{L}$ and $\mathrm{M}$. Abdomen about 1.5 times as long as broad. Genital fold as shown in Fig. 7, P. 


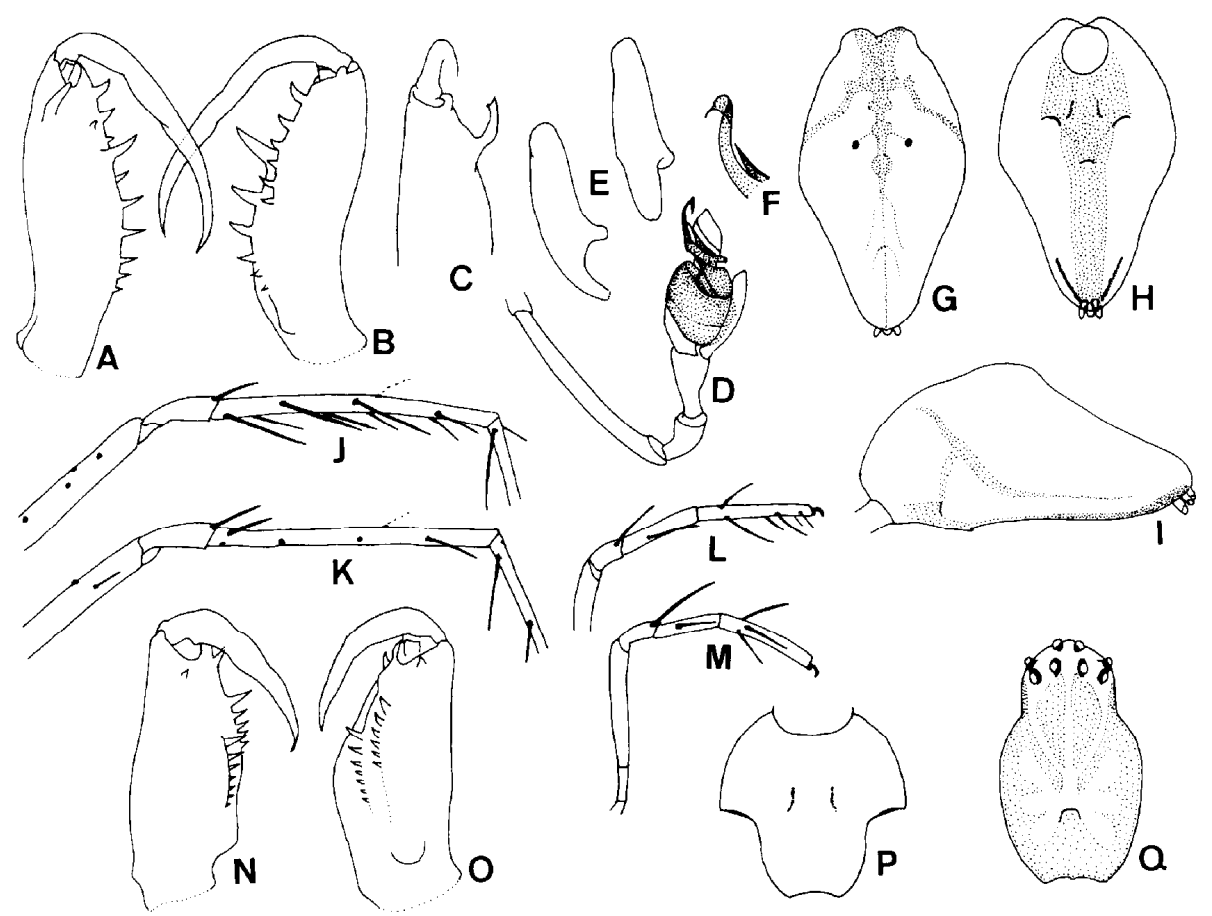

Fig. 7. Tetragnatha restricta Simon. A : Left chelicera of male, upper view. B : Ditto, lower view. C: Ditto, lateral view. D: Left palpus of male, outer lateral view. E: Paracymbium of male. F : Distal portion of conductor of male. G : Abdomen of female, upper view. H : Ditto, lower view. I : Ditto, lateral view. J : Tibia of first leg of female, inner lateral view. $\mathrm{K}:$ Ditto, outer lateral view. L :Palpus of female, inner lateral view. $\mathrm{M}$ : Ditto, outer lateral view. $\mathrm{N}$ : Left chelicera of female, upper view. 0 : Ditto, lower view. P : Genital fold of female. Q : Carapace of male, upper view.

Color : Generally pale yellowish brown ; legs pale reddish brown and with small flecks and dusky rings, although it almost faded ; abdomen pale yellowish brown, except dorsal cardiac area and ventral median area, covered with whitish silvery spangles.

Body length, exclusive of chelicera $5.7 \mathrm{~mm}$; carapacial length $2.0 \mathrm{~mm}$, width 1.6 $\mathrm{mm}$; abdominal length $3.7 \mathrm{~mm}$, width $2.3 \mathrm{~mm}$; height $2.0 \mathrm{~mm}$; cheliceral length 1.2 $\mathrm{mm}$.

Tetragnatha uncifera Simon, 1900 (Fig. 8)

Tetragnatha uncifera Simon, 1900, Fauna Hawaiiensis, 2(5): 474.

Male. Anterior row of eyes occupying full width of head, posterior row of eyes slightly narrower than anterior one; viewed from above, two rows nearly parallel and recurved. Basal segment of chelicerae about 0.8 times as long as carapace ; (a) slightly bifurcated at tip, (Gu) present, (sl) strikingly curved backward, (T) moderately large, 


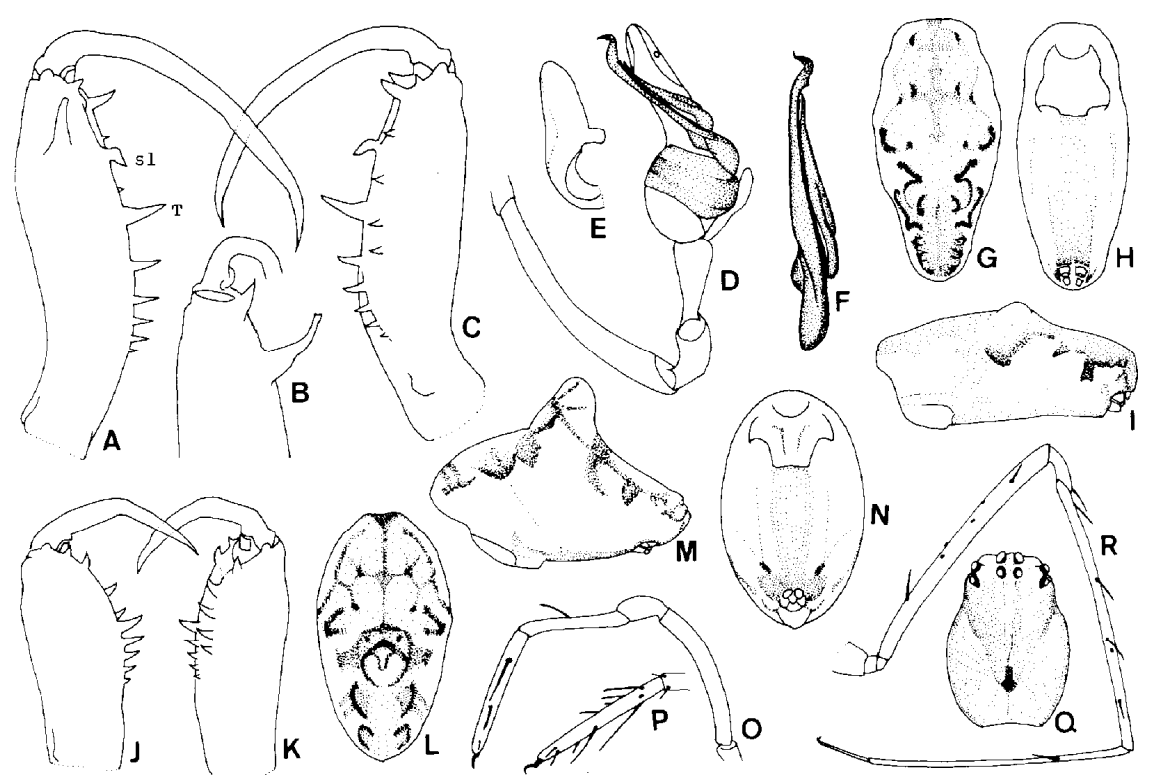

Fig. 8. Tetragnathu uncifera Simon. A : Left chelicera of male, upper view. B : Ditto, lateral view. C: Ditto, lower view. D: Left palpus of male, outer lateral view. E: Paracymbium of male. F: Conductor and embolus of male. G: Abdomen of male, upper view. H : Ditto, lower view. I : Ditto, lateral view. J : Left chelicera of female, upper view. K : Ditto, lower view. L: Abdomen of female, upper view. M : Ditto, lateral view. $\mathrm{N}$ : Ditto, lower view. 0 : Left palpus of female, outer lateral view. P : Tarsus of right palpus of female, inner lateral view. Q : Carapace of female, upper view. R: Right first leg of male, outer lateral view.

(rsu) 5 in number, (AXl) present, (Gl) long and large, (rsl) 4 in number ; fang unarmed. Legs almost damaged ; femur of first leg probably with 9-10 spines (actually broken) ; spines not so long. Tibia of palpus slightly longer than patella; tip of conductor as shown in Fig. 8, D. and F. Abdomen about 2.2 times as long as broad ; distal end of abdomen somewhat overhanging spinnerets.

Color : Carapace chelicerae, sternum and maxillae pale reddish brown, legs pale yellowish brown probably with many small dusky spots (it almost faded now) ; abdomen generally pale yellowish brown, although it almost faded, with dusky markings and covered with whitish spangle.

Body length, exclusive of chelicera, $6.0 \mathrm{~mm}$; carapacial length $2.5 \mathrm{~mm}$, width 1.7 $\mathrm{mm}$; abdominal length $3.5 \mathrm{~mm}$, width $1.6 \mathrm{~mm}$; cheliceral length $2.0 \mathrm{~mm}$.

Female. Arrangement of eyes nearly as in male. Basal segment of chelicera about 0.6 times as long as carapace, without particular features. Femur of first leg probably with 10 spines (actully broken). Tarsus of palpus with many spines as shown in Fig. 8,0 and P. Abdomen about 1.5 times as long as broad, strikingly gibbous dorsally as shown in Fig. 8, M.

Color : nearly as in male. 
Body length, exclusive of chelicera $7.6 \mathrm{~mm}$ : carapacial length $2.8 \mathrm{~mm}$, width 1.8 $\mathrm{mm}$; abdominal length $5.4 \mathrm{~mm}$, width $3.5 \mathrm{~mm}$, height $4.2 \mathrm{~mm}$; cheliceral length 1.8 $\mathrm{mm}$.

\section{REFERENCE}

Simon, E. 1900 Arachnida. In : Fauna Hawaiiensis, 2(5): 443-519, T. 15-19. Paris 